\title{
A Study on the Production Characteristics of Media Contents from the Perspective of Relational Dissemination - A Case Study of Social Media
}

Juan Yao

\author{
School of Wuhan Donghu University, Wuhan 430212, China;
}

\author{
Key words :relational communication content production social media
}

\begin{abstract}
In the age of social media, the mode of communication is changed from content communication to relationship communication. Content communication is a one-way, one-to-many communication activity around the communication content, which belongs to the mass communication era. Relational communication emphasizes the establishment of interactive communication between the communication subject and the audience. In the case of social media micro-letters, the mode of communication shows the "mirror-in-me" type of daily life, and the formation of cultural identity in the transmission of "public events", which hits the social issue of public sentiment. Art and other relations.
\end{abstract}

\section{Introduction}

Mass media age, newspapers, radio, television and other media is the main communication. Mass communication is a one-way, one-to-many dissemination of content around communication content. In the social media age, the mass communication began to be marginalized, and the relationship formed by the social platform became the main mode of communication. The essence of social media is the construction of interpersonal relationship platform, users in the social media platform to share views, ideas and experience, and further through the forward and comment post, user contribution content, private communication, mutual powder interaction Communication activities, the spread of the relationship between virtual space has become a part of social communication, breaking the "from the reality of space and physical perception of the double limit. [1] This article will be social media WeChat as an example, the relationship between the spread of social media content under the production characteristics of analysis.

\section{"Mirror in my" type of daily life status}

"Mirror me" theory by the American social psychologist Cooley put forward. "In many cases, the connection with others depends on a more certain form of imagination, which is to imagine how his own self-consciousness, which is proprietary to him, is present in the consciousness of others, The society can be called self-reflection or self-mirror. "[2] micro-faith circle of friends is like a virtual mirror, the individual in the circle of friends to share food, scenery, parties, love, interesting As well as life sentiment and other immediate life status and emotions, in fact, not the real self, but by imagining others on their attitude, evaluation of performance. Because people have a better, more ideal aspects of self to the other side of the subconscious, therefore, "when the individual appears in front of others, the performance often contains and embodies the community is officially recognized value, and he All the behavior does not have such value. "[3] micro-circle friends through point praise and comment, interactive and strengthen the impression, to maintain such a reality and virtual transfer of social relations, access to real relationships successful achievement sense. 


\section{"Public events" in the form of the transfer of cultural identity.}

Identity is the self-reflection of the subject, cultural identity is the main content of identity, refers to the cultural identity of their own sense of belonging. Cultural identity is a feeling of group cultural identity, a sense of individual being influenced by group culture. Micro-letter features a rich and varied, both instant messaging and line information dissemination function, in the circle of friends and friends from the point of praise, comments, replies are interpersonal feedback, WeChat circle of friends is a interpersonal communication characteristics of group communication. According to the survey, $62.97 \%$ of users in the micro-circle of friends on the main operation is "browsing friends of the state, mood," want to know what friends are doing and indirectly from a friend to learn how to live, life, [4] The Micro-Friend Circle provides a platform for identity in the community.

Identity is cultural identity. German philosopher Cassirer pointed out that people are symbols of animals, culture is the form of symbols, human activity is essentially a "symbol" or "symbolic" activities. Culture is a kind of "root", which precedes the specific individual, through the inheritance of the national characteristics, in the form of "collective unconsciousness" congenital to the individual's mental structure to form a "prototype". Individuals in the socialization, it is natural to show a kind of cultural continuity.

For example, cultural celebrities Wang Guozhen, Chen Zhongshi, Yang Jiang after the death of friends circle scraper. The death of the poet Wang Guozhen triggered a collective memory of youth memory. Chen Zhongshi because of the masterpiece "White Deer" was praised, his death makes people sigh. Yang Jiang's death cherish the memory of life in the dust in the popular public poetry and distant longing, forwarding is a cultural identity.

\section{Social issues that hit public sentiment.}

In the WeChat circle of friends and forward the news is often able to hit the public mood of social topics. At the beginning of March 2015, Chai Jing produced documentary "Dome" in friends circle scraper, the film detonated the public again on the haze of concern and discussion, the formation of social topics. "Chai static phenomenon" because the haze hazard hit the public mood. Haze makes a large area of serious air pollution, toxic air visibility down to 200 meters, the air is full of a lot of harm to human health pollutants. Well-known psychologist Maslow put forward "Maslow's hierarchy of needs theory", including health, including the security needs of people's basic needs, such a topic related to all mankind, will inevitably lead to a heated social debate. Of course, haze and other environmental issues have existed for a long time, their concern is not from the wood Jing Shi. "Under the dome" cause concern, more important is the narrative technique of Chai Jing. Chai Jing in the documentary is not to appear as a bystander, but as a mother appears, this approach is more suitable for interpersonal relationship-based mode of communication, can cause public emotional resonance.

\section{Causing the collective "carnival" behavior art}

December 6, 2015, a lot of people playing WeChat circle of friends to participate in a "mainly to see temperament," Solitaire games, there are two ways to participate in the game, or pick up their photos and named Long "to see temperament" to continue the game, Or to let you move in the WeChat friends made a 5.21 yuan red envelope. Two days, the circle of friends, including netizens, including a variety of stars from the screen scraper, a lot of people involved in the game, this seemingly meaningless games, strong communication in the social media, driven by friends to become lonely, Get the joy of the collective carnival.WeChat as a free social media platform, a collective carnival field. In the carnival, a new kind of interrelationships are formed between people, manifested in the form of concrete perceptual forms, semi-realistic semi-games, which are related to 
the strong social hierarchy in non-carnival life On the contrary, human behavior, gesture, language, from the non-carnival life completely dominate all the various levels of status (class, rank, age, property status) in the liberation of the WeChat in this virtual Cyberspace, Internet users from the reality of the hierarchical order to escape, to participate in the collective "carnival" of the performance art.

These games get friends because of the pro-Lai game can use the relationship between the dissemination of channels, making Internet users have a sense of participation, thus becoming a national entertainment collective carnival. This carnival will be users from the real life into the virtual community, the release of emotions, get relief. In addition, the game even with the herd mentality of the herdsmen are closely related. People in the group environment, the total will be affected by the behavior of the outside crowd, so in their own perception, judgments, understanding, consistent with the public opinion or the behavior of the majority of people. The general group size, cohesion, group consensus, are easy to make individual herd mentality. Therefore, when friends circle friends are involved in a certain game, users will be affected, showing herd mentality.

\section{Conclusion}

From the above, we can see that the contents of the circle of micro-friends show the status of daily life in the mirror, the formation of cultural identity in the transmission of "public events", the social topic of public sentiment, and the behavioral art of collective carnival. Characteristics, and WeChat friends circle specific characteristics of the relationship between the spread. The micro-faith has the characteristics of strong social attribute and weak media attribute, and the circle of friends gathers to form the group relationship. The group relationship is manifested in the interpersonal, social and cultural aspects. At the level of interpersonal communication, the instant messenger of WeChat and the personal self-display in the circle of friends and other peepers all form good emotional interaction and form a virtual emotional bond beyond reality; at the social level, WeChat provides for the public issue Communication and interaction. On the cultural level, the herd mentality in group communication leads to cultural identity. Through the analysis of micro-media content production characteristics, we can see that social media content production is in the relationship between people, between people and media, the relationship between the spread of the content of the transmission of information and user understanding of information .

\section{Acknowledgments}

This article is funded by The Education Science Twelfth Five - Year Plan Key Project of Hubei Province in 2016: A Study on the Application of Internet Thinking in the Training of Media Talents.

\section{References}

[1] Gao Chong, Li Min. The Characteristics and Educational Significance of Social Media Intercourse [J] .Journal of Youth, 2014 (5) [5] Jie Wei. Mobile movie Ca rnival [J]. Internet Weekly, 2004 (33): 72.

[2] Charles Horton. Cooley a package of a Wang source translation. Human nature and social order [M] Huaxia Publishing House, 1989 edition, P118.

[3] Owen Goffman translated by Li Jiang Self-performance in daily life [M]. Yunnan People's Publishing House, 1988 edition, P19.

[4] Here the data refer to the Chen Pei's master's degree thesis "micro-mainstream users of the" use and satisfaction "research"

[5]Bakhtin Dostoevsky. Poetics problem [M]. Joint Publishing, 1988 edition, P176 